was recognized from the outset that the stendard of the surveys from which it would be compiled varied greatly in different parts of the world, but it was felt that if the sheets were published in a uniform style and those features which had only been roughly explored were clearly distinguished, a very useful map would result. It was discussed at succeding (4-yearly) conferences and by 1910 detailed specifications for projection, sheet lines, conventional signs and layer colouring had been drawn up, with the object of ensuring that sheets published by different countries should be as much a part of a uniform series as if they had been issued by the same publisher. By 1914 about a dozen sheets had been published. During the War several sheets were issued in styles closely approximating to that specified, but the Paris Conference of 1913 had ruled that sheets not completely conforming could not be regarded as part of the International Map, and in the first report of the Central Bureau of the Carte International du Monde (1921) two index diagrams were printed-one showing international sheets and the other sheets sufficiently similar to be conveniently used to supplement them. This distinction was confirmed by the conference of 1928 and firmly adhered to in the period between the Wars. Some of the most important contributions, including the American Geographical Society's series of sheөts of Hispanic America, which was commenced in 1922 and completed in 1945 , fall in the latter cate. gory, though they closely resemble International sheets.

In 1939 a map on this scale was again found to be most useful, and many sheets were prepared by military establishments. As time went on, they departed more and more from the specifications for the International Map and by the end of the War the position was very confused. In September 1953 the functions of the Central Bureau at Southampton were transferred to the United Nations Cartographic Office and an attempt was made to find out what had been published. The first result was an index diagram in World Cartography, Vol. 3. The report of the regional cartographic conference referred to above contains a reproduction of this diagram, which bears the date January 1957, though World Cartography, Vol. 4, which was published in the first half of 1956 , and was devoted entirely to the International Map, contains a later diagram showing many more sheets, particularly in Asiatic Russia and Australia. It also contains most useful reproductions of the resolutions of 1913 and 1928.

The report for 1955 on the International Map of the World on the Millionth Scale (published in 1957) again shows more sheets, this time mostly of China. In both cases it is explained that the additional sheets are not necessarily newly published, but that their existence had not previously been reported to the United Nations. However, an inspection of the tabulated list of sheets reveals the fact that a great many, particularly of these additional sheots, are published by either the Geographical Section of the General Staff of Great Britain, or the Army Map Service of the United States, and are for "official use only, and not for sale or distribution". What is not revealed is the equally important fact that in general they depert considerably from the specifications for the International Map, though it is made clear that many of those of Chine are in black-and-white only and in the Chinese language. In fact, almost no reference is made to the distinction so carefully drawn in the years before 1939 between International and other sheets. Since the latter have become so very heterogeneous, some of them having little except projection and sheet lines in common with the International Map, the report is of little value as a guide to the present state of what used to be known as the Carte International du Monde. It would be a great pity if the challenging but very desirable and, one hopes, not unattainable objective of a homogeneous series of maps covering the whole world which for so long received the support of many distinguished geographers and surveyors should become obscured by a welter of second-rate publications, not all of which are even on public sale. A. M. Ferrar

\title{
INSECTS OF MICRONESIA
}

$T^{\mathrm{s}}$ HE attention of students of the terrestrial Arthropoda in general is directed to a series of publications by the Bernice P. Bishop Museum, Honolulu, Hawaii, entitled "Insects of Micronesia". The geographical area covered includes practically all the oceanic islands of the north-western Pacific Ocean west of the 180th meridian and north of the equator. The chief island groups are the Marianas, Carolines, Marshalls and Gilberts, and the isolated islands are Ocean, Nauru, Wake, Marcus, the Bonins and the Volcano Islands. Altogether, Micronesia comprises some 2,400 islands under the adminis. tration of the United States, the United Kingdom and Australia. The former Japanese possessions, the Bonin Islands, Volcano Islands and Marcus, are now under United States mandate.

This series is based largely on the collections made between 1947 and 1953 by the Pacific Science Board (U.S. National Research Council) with the financial support of the U.S. Office of Naval Research, but much material was collected during the Second World War by American Service-men and previously by Japanese workers headed by Prof. Teiso Esaki, of the University of Kyushu. Since 1953 the work has been financed by the U.S. National Science Foundation, which has also assisted in the publication of the series.

"Insects of Micronesia" is planned to appear in twenty volumes which will be published at irregular intervals when ready. Vol. 1, which explains the scope and aims of the series as well as discussing the environment and natural history, was published in 1954 and is by Dr. J. Linsley Gressitt, entomologist at the Bishop Museum and leading spirit in this ambitious project. Vol. 2, published in 1955, is a comprehensive bibliography together with a subject index and is by Prof. Toiso Esaki, E. H. Bryan, jun., and J. L. Gressitt. Vol. 3 will be devoted to the Arachnida, Vol. 4 to the Crustacea, and Vols. 5-19 to the insect orders, followed by a summary in Vol. 20. Although none of these volumes has been completed, twenty-two parts have been issued to date.

This work is being undertaken by 115 specialist authors representing about fifty institutions in some thirteen countries, and is an example of the inter. national effort required to deal with the vast assem. 
blage of insects. Some idea can be gained of the increase in knowledge resulting from this publication by reference to the most recent issue, Vol. 7, No. 3, Heteroptera Aradidae, by Ryuichi Matsuda and Robert L. Usinger, in which the number of known species of this obscure family of fungus-feeding bugs is raised from thirteen to forty.

It is to be hoped that "Insects of Micronesia" will be successfully concluded in the not too distant future.
W. E. China

\title{
A TRAP FOR INSECTS BITING SMALL VERTEBRATES
}

\author{
By DR. W. H. R. LUMSDEN
}

East African Virus Research Institute, Entebbe, Uganda

\begin{abstract}
$\mathbf{N}$ estimating the biting insect attack on man the bait may be made to perform the work of eatching, as in the 24-hr. catch system with human catchers ${ }^{1}$, and so confusing factors are minimized. In the case of other animals, however, a difficulty arises. If men are used for catching the insects alighting to feed on an animal bait, it remains in doubt whether the insects are primarily attracted to the animal or to the men, only biting the animal secondarily. Conversely, some of the insects biting the men might be expected to bite the animal if it was alone. Previous attempts to resolve this difficulty with unattended traps baited with animals have employed traps with restricted inlets ${ }^{2,3}$. Such traps are very successful for some species of mosquito, less so for others, perhaps because species vary widely in their readiness to enter. Further, these traps do not retain all the insects entering them; a certain, probably variable, proportion escapes ${ }^{3}$. The essentials of an improved design appeared to be that access to the bait should be as open as possible and that insects attracted to the bait, and captured, should not be able to escape afterwards. Some reconciliation of these apparently mutually exclusive characteristics has been accom. plished in the trap to be described, which samples at regular intervals the flying insects in the vicinity of a bait which is as nearly as possible freely exposed.
\end{abstract}

A first design of trap ${ }^{4}$ employed a horizontal flow of air over the bait. Although it was successful its efficiency was considered likely to vary with changes in wind direction and velocity, and so it has been superseded by a vertical design (Fig. 1). A 'VentAxia' 12-in. fan is mounted on a framework of iron strip and rod over the centre of a platform of hardboard. The trap is quite open around the platform for a height of $15 \mathrm{~cm}$. Above this, and up to the base of the fan assembly, a conical space is partially enclosed by truncated sectorial pieces of transparent cellulose acetate sheet between the edges of which are spaces about a centimetre wide. The bait, in the middle of the platform, is thus visible from all directions above the horizon except from directly and nearly directly overhead, and access of insects to it is practically unimpeded. Above the fan a metal cylinder carries a wire gauze funnel which leads laterally to a small chamber fitted with a collecting bottle; the bottle contains a killing agent-potassium cyanide or pyrethrum.

The switching of the fan motor is performed by a 'Sunvic' hot-wire vacuum switch, using as a control an ordinary alarm clock the minute hand of which trails a piece of hair-spring over a surface of aluminium foil out of which are cut sectorial pieces to correspond with the desired 'off' periods.

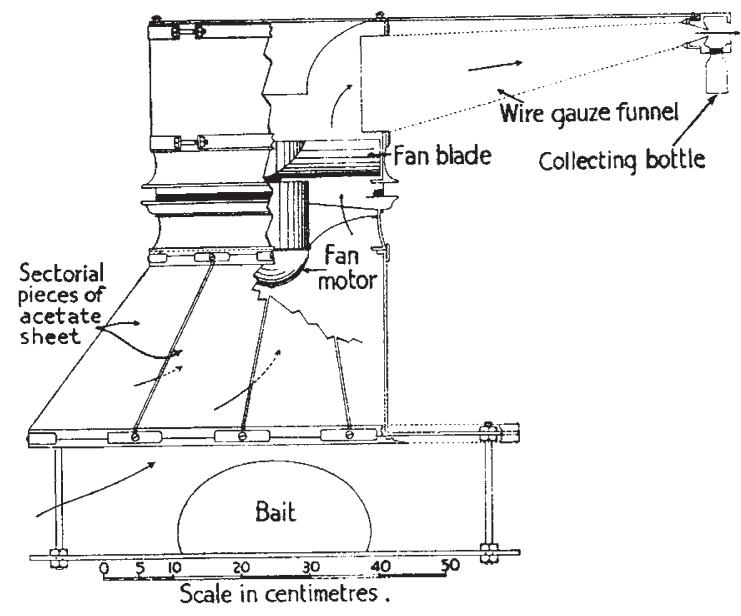

Fig. 1

Comparisons of the performance of the first design of trap on various cycles of operation-continuous running and 'on' and 'off' periods, respectively, and 2 and 3 min., 5 and 5 min., and 2 and $8 \mathrm{~min}$.- led to the selection of 'on' $2 \frac{1}{2}$ and 'off' $5 \mathrm{~min}$. periods giving eight complete cycles per hour. This cycle has been retained in the larger trap with, so far, no further experimentation. Other pilot studies with the first design of trap concerned the effect of different animal baits, the periodicity of activity and the effects of different environments and levels. All these studies gave promising results although the numbers caught were only moderate; for example, in sixteen nights at ground-level in the compound of the Institute, 940 mosquitoes were taken on four guinea pigs as bait-an average of 59 per night. The new design eppears much more effective; under approximately similar conditions both with regard to trap operation and expected mosquito density the new design took 2,449 mosquitoes on one rabbit in five nights, an average of 490 mosquitoes per night.

Some first results to indicate the efficiency of the new design are as follows :

(a) The effect of the bait; 10 all-night runs, alternately with and without a grey rabbit; groundlevel, East African Virus Research Institute compound (see Table 1).

The occurrence of small numbers of mosquitoes in the trap in the absence of bait is to be expected as the trap will catch mosquitoes entering it by chance at the appropriate time. However, in this particular case a cage which, fouled by the animal, may have some attractive power, was present in both series. 